Cite this: Phys. Chem. Chem. Phys., 2011, 13, 12067-12074

\title{
Structural organization and phase behaviour of 1-butyl-3-methylimidazolium hexafluorophosphate: an high pressure Raman spectroscopy study
}

\author{
Olga Russina, ${ }^{a}$ Barbara Fazio, ${ }^{* b}$ Christian Schmidt ${ }^{c}$ and Alessandro Triolo*d
}

Received 27th November 2010, Accepted 5th May 2011

DOI: $10.1039 / \mathrm{c0cp02684k}$

The complexity of the phase diagram of a representative room temperature ionic liquid (1-butyl-3-methylimidazolium hexafluorophosphate, $[\mathrm{bmim}]\left[\mathrm{PF}_{6}\right]$ ) is explored by means of Raman spectroscopy at high pressure (up to $1000 \mathrm{MPa}$ ) and high temperature (from room temperature to $100{ }^{\circ} \mathrm{C}$ ) conditions. The first experimental evidence of the existence of a second crystalline phase for this salt at high pressure conditions is provided. By comparing the low frequency vibrational bands for the liquid state and the two observed crystalline phases, we confirm the scenario that considers the crystal polymorphism in this class of materials as a consequence of the rotational isomerism of the butyl chain. Furthermore the pressure dependence of other vibrational bands indicates the existence of a structural rearrangement across $p \approx 50 \mathrm{MPa}$ at ambient temperature.

\section{Introduction}

Room temperature ionic liquids (RTILs) are an emerging class of materials that shows a number of appealing chemical and physical properties. ${ }^{1-10}$ They are organic salts with a low melting point, conventionally chosen as $100{ }^{\circ} \mathrm{C}$. Moreover, they display large tunability of their chem-physical properties ${ }^{11}$ upon slight changes in their chemical architecture and have a negligible vapour pressure. In the last few years, great attention has been paid to these materials to find many novel applications that exploit these properties.

As representative RTILs, 1-butyl-3-methylimidazolium([bmim]) based salts have been extensively investigated in their structural, dynamic and thermodynamic properties, in particular $[\mathrm{bmim}]\left[\mathrm{PF}_{6}\right]$. Information on its synthesis and applications were provided more than a decade ago. ${ }^{12}$ Details on its phase diagram (melting point, stability temperature range, density, viscosity, etc.) also were reported. ${ }^{13}$ Its thermodynamic properties both in the ideal gas state ${ }^{14}$ and in the condensed state ${ }^{15}$ were reported. More recently a careful report highlighted the existence of three different crystalline phases for this material, on the basis of calorimetric and spectroscopic evidences. ${ }^{16}$

a Dipartimento di Chimica, Università di Roma, 'La Sapienza', P. le Aldo Moro 5, I-00185 Roma, Italy

${ }^{b}$ CNR - Consiglio Nazionale delle Ricerche, Istituto per i Processi Chimico-Fisici, Viale F. Stagno D'Alcontres, 37 I-98158, Messina, Italy.E-mail:fazio@me.cnr.it

${ }^{c}$ GFZ German Research Centre for Geosciences, Telegrafenberg, 14473 Potsdam, Germany

${ }^{d}$ CNR - Consiglio Nazionale delle Ricerche, Istituto Struttura della Materia, Area della Ricerca di Tor Vergata, Via del Fosso del Cavaliere, 100, I-00133 Rome, Italy.E-mail:triolo@ism.cnr.it
Recently the behaviour of RTILs under high hydrostatic pressure has been studied, mainly due to the interest to exploit RTILs for smart applications under extreme conditions.

Transport measurements showed that the self-diffusion coefficients of both cations and anions in $\left[\mathrm{bmim}^{-}\right]\left[\mathrm{PF}_{6}\right]$ strongly decrease upon increase in pressure. $^{17}$ Thermophysical and thermodynamic properties of both $\left[\mathrm{bmim}^{\mathrm{b}}\right]\left[\mathrm{PF}_{6}\right]$ and $[\mathrm{bmim}]\left[\mathrm{BF}_{4}\right]$ under pressure have been studied, including speed of sound and density determinations. ${ }^{18}$ The latter report also provided information on the high pressure-high temperature phase diagram of $[\mathrm{bmim}]\left[\mathrm{PF}_{6}\right]$, which was found to crystallise above room temperature upon application of high enough pressure. No crystallization of $[\mathrm{bmim}]\left[\mathrm{BF}_{4}\right]$ was reported.

More recently at the COIL-2 conference (2007), Sawamura and collaborators described the phase diagram of $\left[\mathrm{bmim}^{\mathrm{m}}\right]\left[\mathrm{PF}_{6}\right]$ over an extended $p-T$ range and reported the existence of a crystalline phase at high $p / T$ [S. Sawamura, S. Kawaguchi, Abstract no. 2P01-008, Proceedings of the Conference on Ionic Liquids 2, August 2007, Japan]. To our knowledge, these data have not been published.

Li et al. reported a high pressure differential thermal analysis (DTA) of $[\mathrm{bmim}]\left[\mathrm{PF}_{6}\right]$ (and $[\mathrm{emim}]\left[\mathrm{PF}_{6}\right]$ ), at pressures up to $1 \mathrm{GPa}$, providing a description for the phase diagram of this salt and highlighting the existence of one crystalline phase over this pressure range. ${ }^{19}$ More recently the same group presented new results based on an extensive high pressure Raman spectroscopy investigation on $[\mathrm{bmim}]\left[\mathrm{PF}_{6}\right]$ up to $2 \mathrm{GPa}$, focusing on the in situ crystallization of this ionic liquid. ${ }^{20}$ This study confirmed their previous results on the existence of one crystalline phase for $[\mathrm{bmim}]\left[\mathrm{PF}_{6}\right]$ under high pressure conditions.

Recently Raman spectroscopy has been successfully applied to RTILs to provide information on their local structure. ${ }^{21-26}$ 
The seminal papers by Hamaguchi and co-workers ${ }^{21-25}$ and Holbrey et $a .^{27}$ described how Raman spectroscopy (and $\mathrm{X}$-ray diffraction) can be used to detect crystal polymorphism in [bmim]-based RTILs. This polymorphism turned out to be the consequence of different conformational organizations of the side butyl chain. In the monoclinic crystalline form, the side chain is all-anti; while in the orthorhombic form, the chain is gauche around the first $\mathrm{C}-\mathrm{C}$ bond departing from the imidazolium ring. Such conformers will be indicated as AA and GA, respectively. It was also shown that $[\mathrm{bmim}]\left[\mathrm{BF}_{4}\right]$ is characterised at room temperature by the coexistence of the two AA and GA conformers. ${ }^{22,24}$

Raman and IR spectroscopy studies have been reported on [bmim] $\left[\mathrm{PF}_{6}\right]$, leading to a rationalisation of the observed experimental features on the basis of ab initio calculations; such studies were useful for the proper assignment of observed bands. ${ }^{26,28}$ As mentioned a recent report from Nishikawa and co-workers used Raman spectroscopy data to characterise the complex polymorphism in $\left[\mathrm{bmim}^{-}\left[\mathrm{PF}_{6}\right]\right.$ at ambient pressure. ${ }^{16}$ The latter study indicates that together with crystalline phases that are characterised by the AA and GA conformers also a crystalline phase where the alkyl chain is in the $\mathrm{G}^{\prime} \mathrm{A}$ conformation can be thermodynamically stable at ambient pressure.

A number of high pressure Raman or IR spectroscopy studies have been presented on [bmim]-based RTILs. ${ }^{29-33}$ Using these techniques, crystalline polymorphism in [bmim] $[\mathrm{X}]$, with $\mathrm{X}=\mathrm{Cl}$ and $\mathrm{Br}$, was studied. ${ }^{29,32,33}$ At ambient pressure, in the liquid state, the two mentioned rotational isomers of the butyl chain (the GA and AA ones) coexist in the [bmim] cation. Upon compression up to $900 \mathrm{MPa}$, the GA conformer becomes progressively de-stabilised. At $1500 \mathrm{MPa}$ a new high pressure crystalline phase forms, which corresponds to a distorted crystal containing the perturbed GA conformer. The crystalline phase stable at ambient pressure, i.e. the one corresponding to the AA conformer, is also switched to a metastable state upon increasing pressure.

Crystal polymorphism in RTILs has been the subject of many studies on the phase diagram and the crystalline phases and to characterise the crystalline phases, as this information is fundamental for smart applications of these materials.

Liquid $[\mathrm{bmim}]\left[\mathrm{PF}_{6}\right]$ solidifies upon application of pressure and crystallises upon heating from the supercooled state. This is not in conflict with reports for $[\mathrm{bmim}]\left[\mathrm{BF}_{4}\right]$, which has not been found to crystallise upon compression at ambient temperature ${ }^{18,31}$ even at $500 \mathrm{MPa}$ (this study, data not shown). Liquid $[\mathrm{bmim}]\left[\mathrm{BF}_{4}\right]$ will eventually solidify if the applied pressure is high enough because the $\mathrm{d} P / \mathrm{d} T$ slope of the melting curve is positive, based on the Clausius-Clapeyron relationship. In addition, no reliable conclusions on phase stability can be drawn from the amount of overpressurization needed for nucleation because of the significance of other factors such as time and availability of nucleation sites.

As recently outlined by Nishikawa and co-workers, ${ }^{16}$ up to three different crystalline phases of this RTIL exist at ambient pressure conditions. Two of these phases were previously investigated. ${ }^{34,35}$ These experimental results are in contrast with recent results from high pressure DTA and Raman experiments, where only one crystalline phase was discernible up to $2 \mathrm{GPa} .{ }^{19,20}$
The existence of different crystalline polymorphs at comparable thermodynamic conditions points to the occurrence of several local conformational minima in the potential energy surface. ${ }^{27}$ This might be one of the reasons for the low melting point and easy supercooling of the liquid state in ILs.

In this study, we present new information on the phase diagram of $[\mathrm{bmim}]\left[\mathrm{PF}_{6}\right]$ over a large $p / T$ window. We will report for the first time the existence of two crystalline phases of $[\mathrm{bmim}]\left[\mathrm{PF}_{6}\right]$ at high pressure and ambient temperature, this occurrence is pointed out by micro-Raman analysis. One of the crystalline phases (the one stable at low pressure) is found to have a melting point in agreement with the previously observed crystal-liquid transition. ${ }^{16,18-20}$ The two crystalline phases are found to show differences in the vibrational bands related to the conformation of the butyl chain, ${ }^{16,21-25}$ thus confirming the well-established view that in these salts the crystal polymorphism is related to the conformational differences in the latter chain. ${ }^{16,21-25,27}$

We will also discuss the pressure dependence of several vibrational bands in the (metastable) liquid state, providing support to the hypothesis ${ }^{30,33}$ that at approx. $50 \mathrm{MPa}$ these salts undergo a structural transition.

\section{Experimental section}

1-Butyl-3-methyl imidazolium hexafluorophosphate, [bmim] $\left.\mathrm{PF}_{6}\right]$, was purchased from Solvent Innovation. The sample that was used belongs to same batch that had been used in our previous characterization of the phase diagram at ambient pressure. ${ }^{35}$ The residual chloride content was $<7 \mathrm{ppm}$, as determined by ion chromatography, and the water content, which was determined by Karl Fischer titration, was found to be $0.0364 \mathrm{wt} \%$ before drying and $0.0124 \mathrm{wt} \%$ after drying. Little hydrolysis of the anion was observed using ion chromatography with a fluoride concentration of $<5 \mathrm{ppm}$. Analysis of the sample by ${ }^{1} \mathrm{H}$ NMR indicated that any impurities, for example, residual $N$-methylimidazole, were below the detection limit. Before all the measurements, the sample was kept under vacuum at $40{ }^{\circ} \mathrm{C}$ for at least $24 \mathrm{~h}$, which allowed moisture and volatile components to be eliminated.

The experiments were performed using a high resolution Raman spectrometer and an externally heated Bassett-type hydrothermal diamond-anvil cell (HDAC) ${ }^{36}$ with ultra-low fluorescence grade anvils. The sample chamber of the cell, a $300 \mu \mathrm{m}$ hole in the Re gasket separating the anvils, was loaded with a grain of quartz, which served as a Raman spectroscopic pressure sensor, ${ }^{37}$ and $[\mathrm{bmim}]\left[\mathrm{PF}_{6}\right]$. Raman spectra of the [bmim] $\left[\mathrm{PF}_{6}\right]$ phases and quartz, and plasma lines were then recorded (a) at constant temperature $\left(20 \pm 0.5{ }^{\circ} \mathrm{C}\right)$ and stepwise increased pressure from 0.1 $\mathrm{MPa}$ to $650 \mathrm{MPa}$, (b) along the $[\mathrm{bmim}]\left[\mathrm{PF}_{6}\right]$ melting curve to $100{ }^{\circ} \mathrm{C}$ and $460 \mathrm{MPa}$, and (c) at $100{ }^{\circ} \mathrm{C}$ and $920 \mathrm{MPa}$.

Unpolarized Raman spectra were obtained using a HORIBA Jobin Yvon LabRAM HR800 UV-Vis Raman microprobe (gratings 1800 lines $\mathrm{mm}^{-1}$, focal length $800 \mathrm{~mm}$ ) equipped with a CCD-detector $(1024 \times 256$ pixel, cooled by a Peltier element). The spectra were recorded in a backscattering geometry with a Nikon SLWD $40 \times$ objective (numerical aperture 0.4) and using the $514 \mathrm{~nm}$ argon ion laser line. 
The laser interference filter was removed to record plasma lines from the $\mathrm{Ar}+$ laser in the same spectrum as the Raman lines. The laser power was set to $35 \mathrm{~mW}$ at the source. At that laser power, no heating of the sample in the HDAC occurs. A confocal pinhole aperture of $100 \mu \mathrm{m}$ was used for good depth resolution. Collection times for Raman spectra of quartz were 5 accumulations of $20 \mathrm{~s}$ each, and for $\left[\mathrm{bmim}^{\mathrm{b}}\right]\left[\mathrm{PF}_{6}\right]$ 10 accumulations of $10 \mathrm{~s}$ each for Raman spectra between 300 to $1300 \mathrm{~cm}^{-1}$ and 20 accumulations of $5 \mathrm{~s}$ each for Raman spectra from 2600 to $3400 \mathrm{~cm}^{-1}$. Before spectra of the fluid were recorded, the nominal focal point position was always set to the same value to obtain comparable integrated intensities of the Raman bands. This was done by focusing on the upper sample chamber surface and then raising the microscope stage by $20 \mu \mathrm{m}$.

Pressures above vapor pressure were obtained from the frequency shift of the $464 \mathrm{~cm}^{-1}$ Raman line of quartz using the eqn (2) and (3) provided in ref. 37. The frequency shift of that quartz line was calibrated by monitoring the plasma line at $520.30 \mathrm{~cm}^{-1}$. The resolution (random error) is about $25 \mathrm{MPa}$. At ambient temperature, the pressures were obtained, with better resolution, from the wavenumber shift of the $206 \mathrm{~cm}^{-1}$ Raman line of quartz, $\left[\left(\Delta \nu_{\mathrm{P}}\right)_{206}\right]$ (eqn (5) of ref. 37, $P(\mathrm{MPa})=$ $\left.0.4633\left[\left(\Delta \nu_{\mathrm{P}}\right)_{206}\right]^{2}+31.66\left(\Delta \nu_{\mathrm{P}}\right)_{206}\right)$. Spectra fitting was done using the software package PeakFit v4.11 from SYSTAT Software Inc., a linear baseline, and the model Pearson IV for the $464 \mathrm{~cm}^{-1}$ Raman line of quartz and the plasma line at $520.30 \mathrm{~cm}^{-1}$ to allow for peak asymmetry. ${ }^{37}$

The K-type thermocouples of the HDAC were attached to the diamond and calibrated using the triple point of water (at $0.01{ }^{\circ} \mathrm{C}$ and $0.6 \mathrm{kPa}$ ) and the $\alpha-\beta$ quartz transition temperature $\left(574{ }^{\circ} \mathrm{C}\right.$ at $\left.0.1 \mathrm{MPa}\right)$. The accuracy and reproducibility of the temperature measurements was better than $\pm 0.5^{\circ} \mathrm{C}$ during acquisition of Raman spectra at temperatures to $100{ }^{\circ} \mathrm{C}$. The power input to the resistive heaters was controlled using Eurotherm ${ }^{\mathbb{R}} 2408$ temperature controllers which held the set temperature within $\pm 0.2{ }^{\circ} \mathrm{C}$ during spectra recording.

\section{Results and discussion}

\section{i Phase diagram determination}

The present report is mainly focused on the study of the liquid state of $[\mathrm{bmim}]\left[\mathrm{PF}_{6}\right]$ and the characterization of its phase diagram (liquid-crystalline phases equilibria) under high pressure conditions. In Fig. 1 we show the results obtained from the Raman measurements at room temperature $\left(T=20{ }^{\circ} \mathrm{C}-293 \mathrm{~K}\right)$ and varying pressure (in the range $0.1-485 \mathrm{MPa})$, in a low frequency region $\left(550-775 \mathrm{~cm}^{-1}\right)$. At ambient pressure Kabo and coworkers reported the melting point of an (unidentified) crystalline phase of $[\mathrm{bmim}]\left[\mathrm{PF}_{6}\right]$ at $283.5 \mathrm{~K} .{ }^{15}$ More recently Nishikawa reported for the same transition a melting point at $284.3 \mathrm{~K} .{ }^{16}$ At ambient temperature, $[\mathrm{bmim}]\left[\mathrm{PF}_{6}\right]$ is thermodynamically stable in its liquid state only up to $c a .50 \mathrm{MPa}$. Above that pressure, de Azevedo et al. ${ }^{18}$ and Li et al. ${ }^{19,20}$ showed that an unidentified crystalline phase gets stable. During our set of measurements, the sample did not crystallise upon pressurising at the mentioned pressure, indicating that it is rather easy to super-pressurize

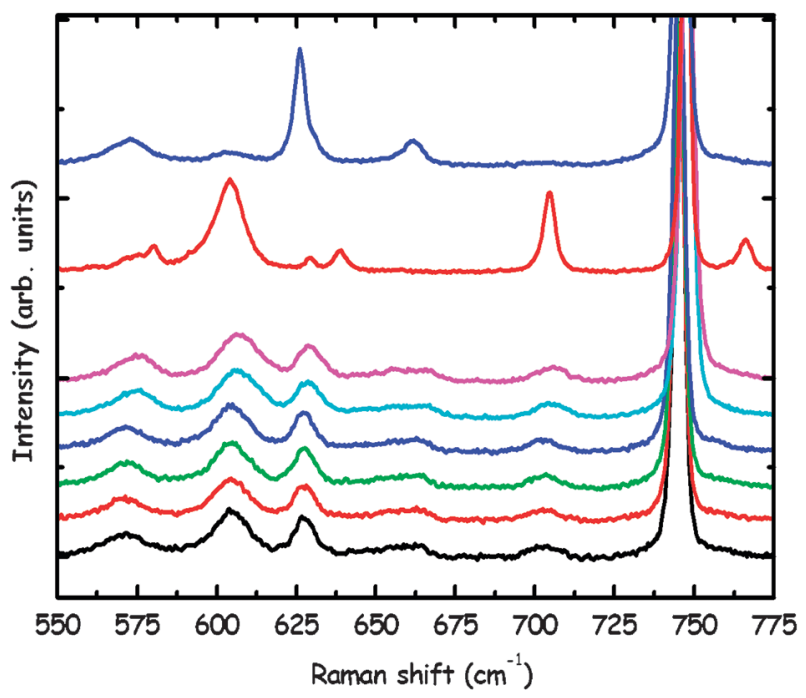

Fig. 1 Low frequency portion of Raman spectroscopy data from 1-butyl-3-methylimidazolium, $[\mathrm{bmim}]\left[\mathrm{PF}_{6}\right]$ at ambient temperature, as a function of pressure. The first six data sets from the bottom refer to data from the (metastable) liquid phase ( $p=0.1,4.0,10.0,18.0,440.0$ and $485.0 \mathrm{MPa}$, from bottom to top), red and blue curves refer to the crystalline phases $\mathrm{S} 1(p=426 \mathrm{MPa})$ and $\mathrm{S} 2(p=48 \mathrm{MPa})$, respectively.

the liquid phase into a metastable liquid state. The sample was pressurised up to $c a .440 \mathrm{MPa}$ (at ambient temperature) and maintained in the liquid state. After 12 hours at these conditions a slight further pressurization led to crystallization into a stable crystalline phase that we will indicate as Solid_1 (S1). Such a phase remained stable at $20{ }^{\circ} \mathrm{C}$ up to the highest pressure that we reached, i.e. $650 \mathrm{MPa}$. Upon pressure decrease (down to $c a .40 \mathrm{MPa}$ ), still at $20{ }^{\circ} \mathrm{C}$, this crystalline phase underwent a phase transition, leading to a new crystalline phase which turns out to show a different Raman spectrum than Solid_1's one (and will be, hereinafter indicated as Solid_2 (S2)).

By raising the temperature and further increasing the pressure, we explored the thermodynamic conditions $(p / T)$ where such a crystalline phase (S2) and the liquid (L) one remain in equilibrium. The range up to $100{ }^{\circ} \mathrm{C}$ was explored and at that temperature the $\mathrm{L}-\mathrm{S} 2$ equilibrium pressure was found to be $465 \mathrm{MPa}$. A comparison between our present equilibrium data and the data reported by de Azevedo et al. ${ }^{18}$ and $\mathrm{Li}$ et al. ${ }^{19,20}$ shows that $\mathrm{S} 2$ corresponds to the same crystalline phase whose melting point had been previously investigated. Such a comparison is presented in Fig. 2.

The data of Fig. 2 show a very good agreement for S2's melting points as obtained by the three other groups (including the Sawamura unpublished data) with our present characterization. The overall $p-T$ data set for the melting points obtained by the combination of de Azevedo's ${ }^{18}$ and $\mathrm{Li}^{1}{ }^{19}$ data sets (the latter data set was considered only up to $60{ }^{\circ} \mathrm{C}$, as at higher temperatures it strongly deviates from the linear trend observed by us) and our present one, which extends the $p-T$ range up to $100{ }^{\circ} \mathrm{C}(373 \mathrm{~K})$ and $465 \mathrm{MPa}$, is qualitatively described with a linear dependence with a slope $\mathrm{d} p / \mathrm{d} T=$ $5.2 \pm 0.1 \mathrm{MPa} \mathrm{K}^{-1}$ over the range $12-100{ }^{\circ} \mathrm{C}(285-373 \mathrm{~K})$ (to be compared with $4.87 \mathrm{MPa} \mathrm{K}^{-1}$ over the range 285-303 K, obtained by de Azevedo et al., ${ }^{18}$ and the two values 5.6 


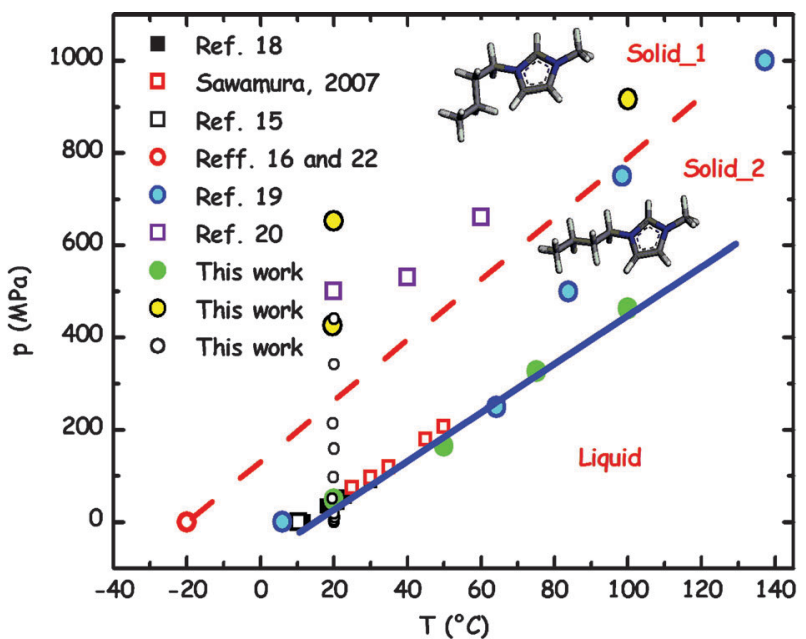

Fig. 2 Phase diagram of 1-butyl-3-methylimidazolium, [bmim] $\left[\mathrm{PF}_{6}\right]$. Results from several characterizations are reported. The equilibrium between the liquid and S2 phases is described using a blue continuous line. This is obtained by linear fit of the data from studies of de Azevedo et al. ${ }^{18}$ (full black squares), Sawamura et al. [unpublished data] (open red squares), $\mathrm{Su}$ et al. ${ }^{19}$ (light blue circles, data are considered in the fit up to $60{ }^{\circ} \mathrm{C}$ ) and us (green circles). The open red circle refers to our previous characterization of the equilibrium between $\mathrm{S} 1$ and $\mathrm{S} 2$ at ambient pressure ${ }^{35}$ and the similar result from Choudhury et $a l .{ }^{34}$ The open black square refers to the liquid-S2 equilibrium characterized by Kabo et al. ${ }^{15}$ The small open black circles refer to the experimental points where Raman measurements were collected in the present study on the (metastable) liquid sample at ambient temperature. The yellow circles refer to the thermodynamic states where Raman spectroscopy data sets correspond to the pattern for S1. The chemical architecture drawn in the figure represents a schematic description of the conformation of the butyl chains in the two crystalline phases (either GA for S1 or AA for S2).

(at $200 \mathrm{MPa}$ ) and 5.0 $\mathrm{MPa} \mathrm{K}^{-1}$ (at $0.1 \mathrm{MPa}$ ) over the range 293-323 K, obtained by Sawamura et al. [S. Sawamura, S. Kawaguchi, Abstract no. 2P01-008, Proceedings of the Conference on Ionic Liquids 2, August 2007, Japan]). These data are compared in Fig. 2 with results from the recent reports from $\mathrm{Su}$ et al. obtained using DTA and Raman spectroscopy, respectively. ${ }^{19,20}$ Only their data for $p<200 \mathrm{MPa}$ agree with our present results as well as the ones from the other mentioned groups. In particular the results from Su's DTA measurements agree with the curve obtained for the S2-L equilibrium. ${ }^{19}$ We then propose that the crystalline phase observed in the Su's DTA measurements is the S2 one.

Upon further increase in pressure from the state $\left[T=100{ }^{\circ} \mathrm{C}\right.$; $p=465 \mathrm{MPa}$, we observed a phase transition from Solid_2 to Solid_1 at ca. $90{ }^{\circ} \mathrm{C}$, but we could not safely determine the corresponding transition pressure.

In the past, Winterton's ${ }^{34}$ and our $^{35}$ groups identified a transition temperature between two crystalline phases at ambient pressure at $c a .-10{ }^{\circ} \mathrm{C}$ and $-20{ }^{\circ} \mathrm{C}$ respectively. The latter thermodynamic point (obtained in ref. 35 for the same sample used in this report) is reported in Fig. 2.

While we were able to characterise in detail the equilibrium between S2 and liquid phases, we have only qualitative description for S2-S1 transition, as we know the transition point detected at ambient pressure (as mentioned above) and

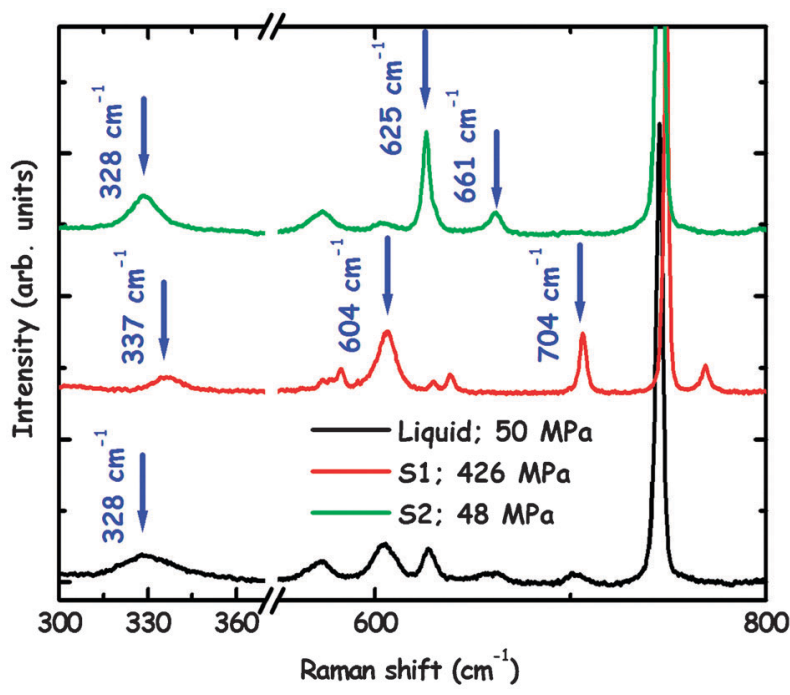

Fig. 3 Low frequency portion of Raman spectroscopy data from 1-butyl-3-methylimidazolium, [bmim] $\left.\mathrm{PF}_{6}\right]$, at ambient temperature, at different pressures. The curves refer to the three different phases that have been observed in the present study: (a) liquid (black line, $p=$ $50 \mathrm{MPa}$ ); (b) crystalline S2 (green line, $48 \mathrm{MPa}$ ); and (c) crystalline S1 (red line, $p=426 \mathrm{MPa}$ ). The arrows indicate the bands that are fingerprints of the two butyl chain conformations. Data have been arbitrarily vertically shifted for clarity.

one point at approx. $90{ }^{\circ} \mathrm{C}$, but undetermined pressure. In Fig. 2 we indicate the corresponding equilibrium curve with a dashed line that has only a qualitative meaning.

In Fig. 3, we present a comparison between the Raman patterns from the liquid and the two crystalline phases (at different thermodynamic states) in the range $300-800 \mathrm{~cm}^{-1}$. In particular all measurements were collected at $20{ }^{\circ} \mathrm{C}$, but $\mathrm{S} 1$ was characterised at $426 \mathrm{MPa}$, while $\mathrm{S} 2$ was studied at $48 \mathrm{MPa}$. For comparison, Raman spectra for the metastable liquid state at $50 \mathrm{MPa}$ is shown, as well. The comparison between the two crystalline phases shows that $\mathrm{S} 1$ is characterised by Raman bands at 604 and $704 \mathrm{~cm}^{-1}$ that have no (or just a minor, in the case of the $604 \mathrm{~cm}^{-1}$ band) counterpart in the case of S2's Raman spectrum. On the other hand, the latter crystalline phase is characterised by Raman bands at 625 and $661 \mathrm{~cm}^{-1}$ that have no counterpart in the S1 spectrum. A number of theoretical and experimental studies indicate the Raman bands at ca. 600 and $700 \mathrm{~cm}^{-1}$ as the fingerprints of the gauche conformation of the side butyl chain, that implies that S1 is characterised by the GA conformation; on the other hand the band at $625 \mathrm{~cm}^{-1}$ has been related to the all-anti conformation of the butyl chain. ${ }^{21}$ For the case of bmimCl, ab initio Density Functional Theory calculations showed that the $625 \mathrm{~cm}^{-1}$ Raman band of the all anti form and the $603 \mathrm{~cm}^{-1}$ band of the gauche conformation are related to an analogous deformation vibrations of the imidazolium ring but that they differ in the coupling scheme with the $\mathrm{CH}_{2}$ rocking vibration of the $\mathrm{C} 8$ methylene group, on account of the different conformation around the C7-C8 bond. ${ }^{22}$ Accordingly we can conclude that the two crystalline phases that are observed in the present case of $[\mathrm{bmim}]\left[\mathrm{PF}_{6}\right]$ are characterised, as in the case of the chloride salt, by a different conformation of the butyl chain. The latter effect is then confirmed to be strongly related to 
(if not responsible of) the crystalline polymorphism in [bmim]related RTILs. Moreover our identification of the different phases is in agreement with the study conducted by Winterton and co-workers: ${ }^{34}$ the authors grew a $\left[\mathrm{bmim}^{2}\right]\left[\mathrm{PF}_{6}\right]$ single crystal at $-30{ }^{\circ} \mathrm{C}$ and then collected the $\mathrm{X}$-ray diffraction measurements at $-80{ }^{\circ} \mathrm{C}$ (at ambient pressure): both thermodynamic states correspond, according to the phase diagram proposed in Fig. 2, to the S1 crystalline phase, that both Winterton and our present characterization identify as characterised by a GA conformation of the butyl chain.

So far there are no existing structural studies on the S2 structure, although in our previous report we showed powder diffraction data at ambient pressure for this crystalline phase, that we did not refine so far. ${ }^{35}$

A specific attention is now paid to the Raman spectra of Fig. 3 in the range $300-350 \mathrm{~cm}^{-1}$. Nishikawa and co-workers recently highlighted the existence of three different crystalline phases for $[\mathrm{bmim}]\left[\mathrm{PF}_{6}\right]$ at ambient pressure. ${ }^{16}$ In their study they show that phase $\beta$ (as indicated by Nishikawa) has a distinguishable band at $624 \mathrm{~cm}^{-1}$. This allows us to identify this phase as the $\mathrm{S} 2$ one that we are presently detecting in our high pressure study. Moreover they notice that the crystalline phases $\alpha$ and $\gamma$ are both characterised by Raman bands at 600 and $700 \mathrm{~cm}^{-1}$. This result would make it difficult to identify in view of our present high pressure study the nature of phase S1. Phases $\alpha$ and $\gamma$ however differ for their bands in the region $300-350 \mathrm{~cm}^{-1}$. In particular Nishikawa et al. highlighted that the Raman bands centred at 338 and $326 \mathrm{~cm}^{-1}$ are the fingerprints for the GA and $\mathrm{G}^{\prime} \mathrm{A}$ conformers $(\alpha$ and $\gamma$ phases, respectively), respectively. ${ }^{16}$ Accordingly we can indicate the crystalline phase $\alpha$ as our presently highlighted phase S1. We can then consider the thermal event observed by Nishikawa at $250.3 \mathrm{~K}$ at ambient pressure for the $\alpha \rightarrow \beta$ transition as part of the phase diagram reported in Fig. 2, describing the equilibrium between $\mathrm{S} 1$ and $\mathrm{S} 2$.

Only the recent reports by $\mathrm{Li}$ and co-workers ${ }^{19,20}$ (using DTA and Raman techniques) accessed a sufficiently large $p / T$ window to be compared with our present characterization of the phase diagram of $[\mathrm{bmim}]\left[\mathrm{PF}_{6}\right]$. The study based on DTA measurements ${ }^{19}$ detected the existence of just one crystalline phase, whose transition to the liquid state follows the behaviour found by de Azevedo and co-workers, ${ }^{18}$ Sawamura and co-workers [unpublished data] and us (this work) up to $65{ }^{\circ} \mathrm{C} / 250 \mathrm{MPa}$ for the $\mathrm{S} 2-\mathrm{L}$ equilibrium. Above this temperature/pressure the melting line of this crystalline phase (our S2) deviates from the trend that our study indicates (we notice that the other studies do not access this high $p / T$ range). Furthermore that study misses the detection of the second (stable at higher pressure) crystalline phase S1. Our opinion is that the observed disagreement might be the consequence of some hysteresis effect during the DTA measurements that were collected at a heating rate of $5{ }^{\circ} \mathrm{C} \mathrm{min}^{-1}$ at constant pressure. Such a heating rate might be adequate to ensure equilibrium conditions at low enough pressure, but might be too high when probing high pressure conditions. The more recent measurements from Su and co-workers were based on Raman spectroscopy and covered a pressure range up to $2 \mathrm{GPa} .{ }^{20}$ Also this study individuates just one crystalline phase, but as the authors notice in their paper "the $S$-L line of the solid-liquid transition of [BMIM][PF6] is different from that gained in the high pressure DTA measurements."20 The authors provide an explanation for this discrepancy and relate it to the different sensitivity of the two techniques. We reported the S-L equilibrium curve obtained in the latter study in the phase diagram of Fig. 2. These results strongly deviate from the ones available for the S2-L equilibrium. However an inspection of the data reported in Fig. 3 of ref. 20 indicates that the crystalline phase is characterised by Raman bands centred at 600, 700, 765,1139 and $1171 \mathrm{~cm}^{-1}$ that are also found in the Raman spectra observed in the present study for the crystalline phase S1. Our rationalisation for the discrepancies found by $\mathrm{Su}$ and co-workers, in view of the presently presented results on the polymorphism in $[\mathrm{bmim}]\left[\mathrm{PF}_{6}\right]$, can then be that the authors of ref. 19 and 20 observed the transitions of different crystal phases with the liquid phase in their two studies. The Raman data $^{20}$ reported by $\mathrm{Su}$ and co-workers during the pressurization of $[\mathrm{bmim}]\left[\mathrm{PF}_{6}\right]$ at ambient temperature confirm our description of the phase diagram reported in Fig. 2. These authors observe the transition L.S (our S1 crystalline phase) at approximately $500-620 \mathrm{MPa}$. This is consistent with our observation that the liquid state can be easily overpressurised into a metastable state without crystallizing and, in agreement with our phase diagram at ambient temperature and at pressures of the order of 500-600 MPa, the stable crystalline phase is the S1. A first glance to Fig. 5 of ref. 20 and its description from the authors indicate that upon de-compressing the $\mathrm{S} 1$ phase stable at high pressure and room temperature, one obtains a transition S1.L. This would not be in agreement with our phase diagram that proposes the existence at ambient temperature of an equilibrium S1-S2, before S2 can transform into the liquid state at low enough pressures. As a matter of fact a careful inspection of Fig. 5 of ref. 20 confirms our proposal: it is clear from the four lowest pressures reported by the authors that upon decompressing the sample, the authors are actually observing the mentioned S1-S2 and S2-L transitions, in agreement with our proposal for the phase diagram.

\section{ii Effect of pressure on Raman vibrational bands}

The low frequency parts of the Raman spectra for the liquid $[$ bmim $]\left[\mathrm{PF}_{6}\right]$ at selected pressures are plotted in Fig. 1. The observed data at ambient pressure are in agreement with results from previous reports at ambient conditions, for this RTIL. $^{26,28}$ As observed by many groups, the liquid state of [bmim] $\left[\mathrm{PF}_{6}\right]$ is characterised by the coexistence of the AA and GA conformers of the butyl chain. ${ }^{21-25,33}$ This is evidenced by the simultaneous presence of Raman bands at 625 and $661 \mathrm{~cm}^{-1}$ and 600 and $700 \mathrm{~cm}^{-1}$, respectively. Hamaguchi and coworkers showed that the coexisting conformers are in thermal equilibrium and upon changing the temperature, such an equilibrium is affected (for example, in the case of bmimCl, upon changing the temperature from $100{ }^{\circ} \mathrm{C}$ to $50{ }^{\circ} \mathrm{C}$, the amplitude of the bands at 600 and $700 \mathrm{~cm}^{-1}$ increases, while the band at $625 \mathrm{~cm}^{-1}$ barely changed). ${ }^{21}$

In order to explore the effect of hydrostatic pressure on such a populations equilibrium in the liquid state, we fitted these Raman bands with Voigt functions. We observe a distinct blue-shift of both bands, upon raising the pressure. These findings 


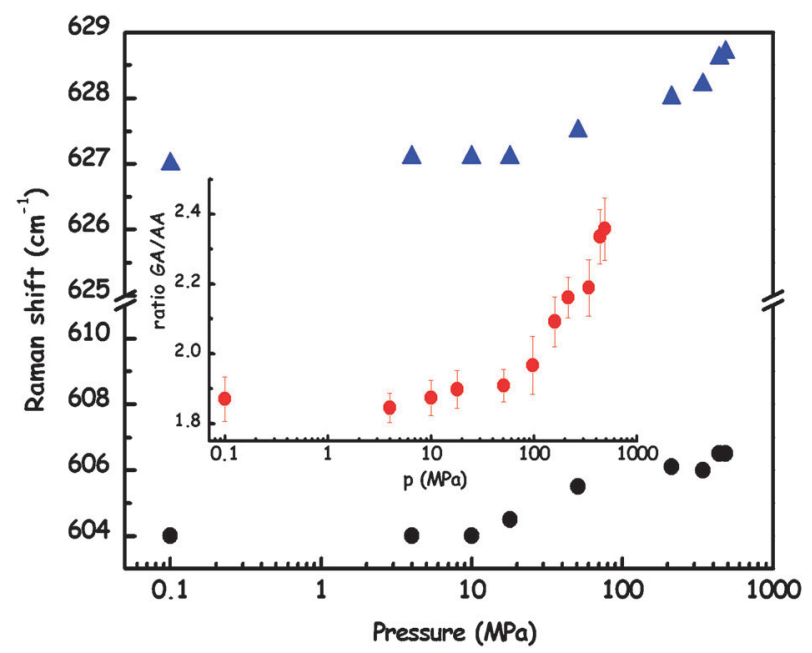

Fig. 4 Pressure dependence of the positions of the bands associated to the AA and GA butyl chain conformers in 1-butyl-3-methylimidazolium, $[\mathrm{bmim}]\left[\mathrm{PF}_{6}\right]$ at $20^{\circ} \mathrm{C}$. In the inset the ratio between the peak areas $(\mathrm{GA} / \mathrm{AA})$ is presented as a function of pressure at $20{ }^{\circ} \mathrm{C}$.

should be compared with the corresponding findings from Chang and co-workers on liquid supercooled [bmim] $\mathrm{Cl},{ }^{30}$ where the authors find that both the bands at 600 and $623 \mathrm{~cm}^{-1}$ show a blue-shift upon increasing the pressure. Similar results were also found by Chang et al. in ref. 33. This feature was related by the authors to the overlap repulsion that is enhanced by hydrostatic pressure; however the pressure resolution in the mentioned study did not allow the authors to appreciate the details that we observe in this work on [bmim] $\left[\mathrm{PF}_{6}\right]$.

In Fig. 4 we show the positions of both bands that are found to just slightly depend on pressure up to $c a$. $50 \mathrm{MPa}$. Above that pressure a blue-shift is observed for the positions of both bands. Interestingly the ratio of the bands' areas (that is related to the ratio between GA and AA populations) follows a similar trend: it maintains rather constant up to $c a$. $50 \mathrm{MPa}$ and, once above that threshold it substantially increases (see the inset of Fig. 4). Our visual inspection during the measurements indicates that the sample maintained in the (metastable) liquid state across the pressure range from ambient up to $485 \mathrm{MPa}$; accordingly the observed change in GA/AA population and the blue-shift in bands positions are not to be related to the occurrence of a first order phase transition, but are presumably related to some structural re-arrangement of the liquid state that is induced by the pressure increase. We additionally propose that the observed behaviour might be a fundamental step in the crystallization of the sample: Fig. 2 shows that all the existing experimental studies converge in indicating at approximately 40-50 $\mathrm{MPa}$ the pressure of liquid to crystalline transition at $20{ }^{\circ} \mathrm{C}$, when no metastable conditions are encountered. Although our system remained in the liquid state during the whole pressure scan up to $485 \mathrm{MPa}$ (both visual inspection and Raman patterns indicate the absence of a crystalline phase during this experiment), the distinct change in the GA and AA populations across the pressure of $c a$. $50 \mathrm{MPa}$ might be a fundamental step in the development of the crystalline phase from the liquid one. In the present case, although this population change occurred, the sample remained in an metastable liquid state. So far, to our knowledge, no more precise studies have been reported in this pressure range to better define the situation.

A similar discontinuity is observed in the behaviour of the room condition stable [bmim]Br crystalline phase: Chang et al. ${ }^{33}$ found that the bands at 600 and $700 \mathrm{~cm}^{-1}$ (related to the GA conformer) show a blue-shift in frequency; they also find the occurrence of a discontinuity in these bands positions around $300 \mathrm{MPa}$. The limited number of measurements in the low pressure regime by Chang and co-workers ${ }^{33}$ does not allow however to determine whether these findings agree with our observation of a transition at $c a$. $40 \mathrm{MPa}$. The authors relate this transition in crystalline [bmim] Br to the formation of a new high pressure phase characterised by a perturbed GA conformer. Although we cannot safely relate our observation to the ones from Chang et al. ${ }^{33}$ on a crystalline IL, these observations seem to converge to the conclusion that the transition at $c a$. $50 \mathrm{MPa}$ that is observed both in liquid and crystalline samples is related to a structural re-arrangement involving the cation and not to a phase transition.

In Fig. 5 we report the pressure dependence of the Raman $\mathrm{C}-\mathrm{H}$ stretching region. In agreement with the findings for [bmim $]\left[\mathrm{PF}_{6}\right]$ from Chang et al., ${ }^{30}$ who explored this frequency range over a wider pressure range using IR spectroscopy, an increase in pressure leads to a distinct blue-shift of the $\mathrm{C}-\mathrm{H}$ stretching bands. We modelled the imidazolium ring $\mathrm{C}-\mathrm{H}$ stretching region between 3075 and $3250 \mathrm{~cm}^{-1}$ with four Voigt functions whose centres's pressure dependence is plotted in Fig. 6. The observed trend can be rationalised in terms of a gradual shift of the peaks positions that saturates to a high pressure limit above $c a .300 \mathrm{MPa}$. This is in agreement with the findings from Chang's experiments, ${ }^{16}$ which however were lacking experimental points in the pressure regime that we are presently exploring. In this respect, our findings are useful to indicate the gradual evolution of the peaks blue-shift, that could not be precisely determined in the previous reports; our results however do not extend above $500 \mathrm{MPa}$ so they cannot

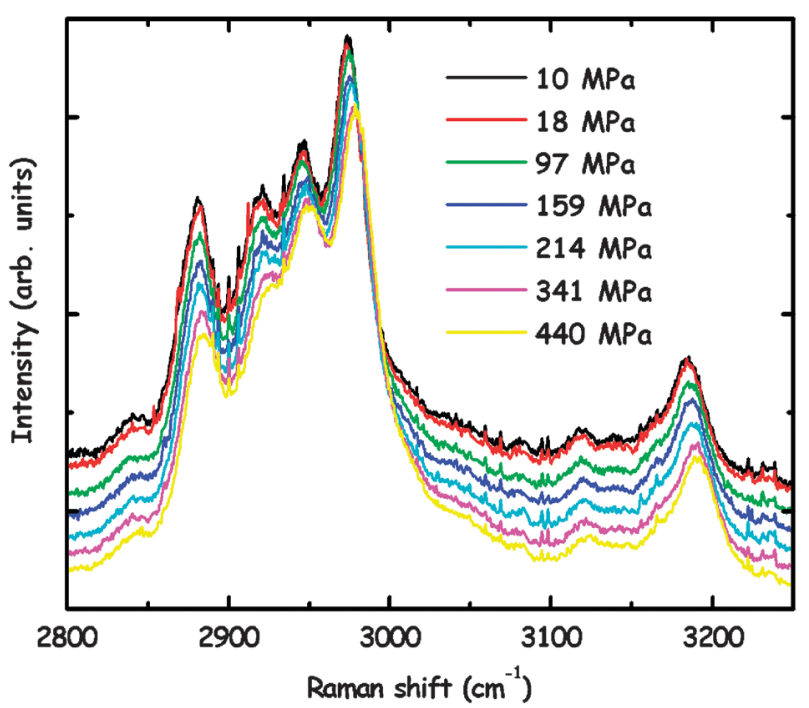

Fig. 5 Pressure dependence of the imidazolium ring $\mathrm{C}-\mathrm{H}$ stretching bands portion of the Raman pattern of liquid 1-butyl-3-methylimidazolium, $\left[\mathrm{bmim}^{\mathrm{b}}\right]\left[\mathrm{PF}_{6}\right]$, at ambient temperature. 


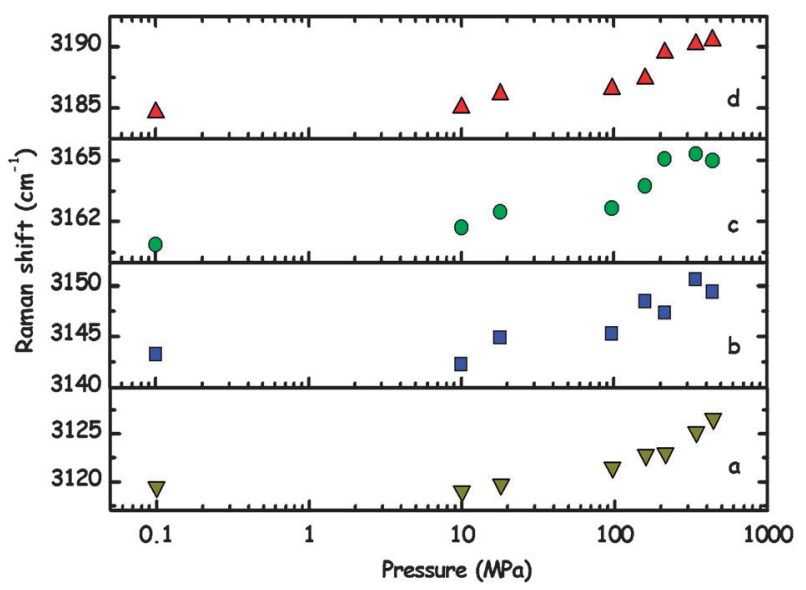

Fig. 6 Pressure dependence of the Raman imidazolium ring $\mathrm{C}-\mathrm{H}$ stretching bands positions for liquid 1-butyl-3-methylimidazolium, $[\mathrm{bmim}]\left[\mathrm{PF}_{6}\right]$, at ambient temperature.

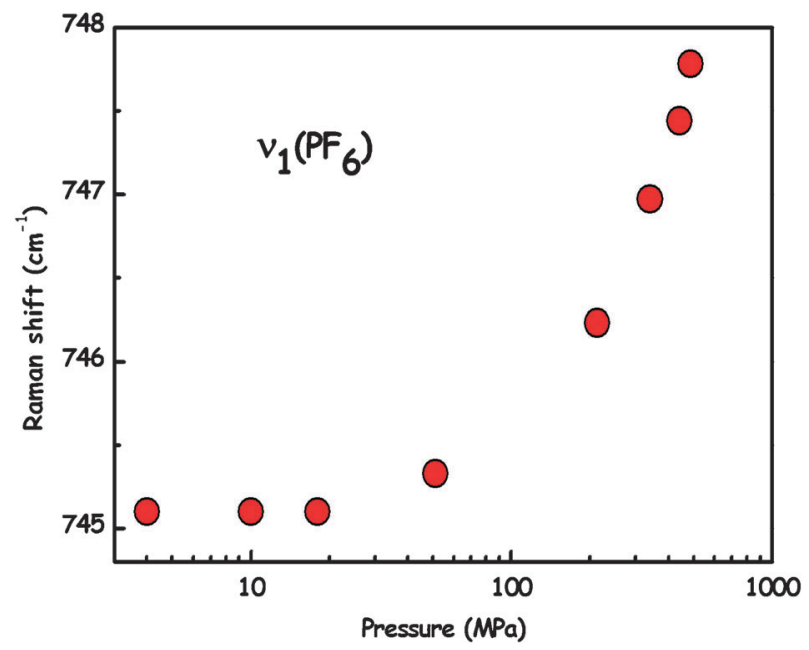

Fig. 7 Pressure dependence of the Raman P-F stretching band positions for liquid 1-butyl-3-methylimidazolium, $\left[\mathrm{bmim}^{-}\left[\mathrm{PF}_{6}\right]\right.$, at ambient temperature.

be further compared with Chang's observation that a further blue shift is observed above $1500 \mathrm{MPa}^{16}$ Chang and co-workers related the observed shifts to the formation of hydrogen bond between the ring hydrogen atoms and the $\mathrm{PF}_{6}{ }^{-}$anion. ${ }^{16}$ This rationalisation can be confirmed on the basis of the $\mathrm{P}-\mathrm{F}$ stretching frequency (that falls at $c a .745 \mathrm{~cm}^{-1}$ ): this vibration also shows a non-monotonous blue-shift, with a distinct up-turn triggering at $c a .50 \mathrm{MPa}$ (Fig. 7), similarly to the behaviour found for the imidazolium ring $\mathrm{C}-\mathrm{H}$ stretching. Our data set then provides further support to the proposal by Chang et al. that the transition may be related to a re-organization of the $\mathrm{C}-\mathrm{H} \cdots \mathrm{F}$ hydrogen bond interaction. ${ }^{30}$ Our results show, however, that the steep blue-shift is gradual (similarly to the observation done for the low frequency bands) and is the consequence of a structural re-arrangement.

\section{Conclusions}

We used Raman spectroscopy to access new details on the phase diagram of a largely studied RTIL, namely 1-butyl-3-methylimidazolium hexafluorophosphate, $\left[\mathrm{bmim}^{-}\right]\left[\mathrm{PF}_{6}\right]$, over a wide temperature-pressure range (from 20 to $100{ }^{\circ} \mathrm{C}$ and from ambient pressure up to $c a .1000 \mathrm{MPa}$ ). Although the sample can be easily kept in a metastable liquid state, we found experimental evidences of the existence of two crystalline phases at ambient temperature. These crystalline phases are the same that were previously identified at ambient pressure, at sub-ambient temperature and are characterised by a different conformation of the side alkyl tail, in agreement with previous observations at ambient pressure and as a function of pressure in the case of halide-based ILs. Our present study did not allow the detection of the third crystalline phase that was recently detected by the Nishikawa group. ${ }^{16}$ The present study furthermore provides a better clarification for the nature of the phase diagram of $[\mathrm{bmim}]\left[\mathrm{PF}_{6}\right]$ and rationalises a few discrepancies that were recently observed in the crystal-liquid transitions for this important RTIL. At the characteristic pressure where the transition liquid-S2 occurs, we observed (even in the metastable liquid state) a distinct transition of the GA/AA population ratio for the butyl chain: we propose that this transition is a necessary (though not sufficient) step for the liquid to crystal transition. Moreover, at ambient temperature, across a pressure of approx. $50 \mathrm{MPa}$, further steep blue-shifts are observed for the vibrational frequencies associated to different groups, such as the $\mathrm{P}-\mathrm{F}$ stretching and the imidazolium ring $\mathrm{C}-\mathrm{H}$ stretching, thus reflecting the complexity of the proposed structural re-arrangement.

\section{Note added in proof}

Together with the mentioned work from de Azevedo, ${ }^{18}$ we just became aware that also Yoshimura and coworkers did not observe crystallization events in $[\mathrm{bmim}]\left[\mathrm{BF}_{4}\right] .^{38}$ After acceptance of the manuscript, we became aware of the very recent work from Takekiyo and coworkers reporting on the detection of one crystalline phase for $[\mathrm{bmim}]\left[\mathrm{PF}_{6}\right]$ under high pressure conditions. ${ }^{39}$ This crystalline phase corresponds to the one that we identify as Solid_1 in the present manuscript.

\section{Acknowledgements}

AT wishes to thank Prof. K. Nishikawa (Chiba Univ.) for kindly making the relevant Raman data-sets of their ref. 16 available to us. AT also thanks Prof. Fangfei (Jilin University) for providing selected data reported in his paper (ref. 20). AT acknowledges support from the FIRB "Futuro in Ricerca" research project (RBFR086BOQ_001, "Structure and dynamics of ionic liquids and their binary mixtures"). AT and BF's activity was in the framework of the CNR-FCT bilateral scientific cooperation agreement (2011/2012).

\section{References}

1 T. Welton, Chem. Rev., 1999, 99, 2071.

2 D. B. Zhao, M. Wu, Y. Kou and E. Min, Catal. Today, 2002, 74, 157-189.

3 W. Lu, A. G. Fadeev, B. H. Qi, E. Smela, B. R. Mattes, J. Ding, G. M. Spinks, J. Mazurkiewicz, D. Z. Zhou, G. G. Wallace, D. R. MacFarlane, S. A. Forsyth and M. Forsyth, Science, 2002, 297, 983-987.

4 K. R. Seddon, J. Chem. Technol. Biotechnol., 1997, 68, 351-356. 
5 C. Chiappe and D. Pieraccini, J. Phys. Org. Chem., 2005, 18, 275-297.

6 M. Antonietti, D. B. Kuang, B. Smarsly and Z. Yong, Angew. Chem., Int. Ed., 2004, 43, 4988-4992.

7 S. G. Cull, J. D. Holbrey, V. Vargas-Mora, K. R. Seddon and G. J. Lye, Biotechnol. Bioeng., 2000, 69, 227-233.

8 F. van Rantwijk, R. M. Lau and R. A. Sheldon, Trends Biotechnol., 2003, 21, 131-138.

9 H. Weingärtner, Angew. Chem., Int. Ed., 2008, 47, 654-670.

10 E. W. Castner and J. F. Wishart, J. Chem. Phys., 2010, 132, 120901.

11 M. Freemantle, Chem. Eng. News, 1998, 76, 32-37.

12 P. A. Z. Suarez, J. E. L. Dullius, S. Einloft, R. F. DeSouza and J. Dupont, Polyhedron, 1996, 15, 1217-1219.

13 J. G. Huddleston, A. E. Visser, W. M. Reichert, H. D. Willauer, G. A. Broker and R. D. Rogers, Green Chem., 2001, 3, 156-164.

14 Y. U. Paulechka, G. J. Kabo, A. V. Blokhin, O. A. Vydrov, J. W. Magee and M. Frenkel, J. Chem. Eng. Data, 2003, 48, $457-462$

15 G. J. Kabo, A. V. Blokhin, Y. U. Paulechka, A. G. Kabo, M. P. Shymanovich and J. W. Magee, J. Chem. Eng. Data, 2004, 49, 453-461.

16 T. Endo, T. Kato, K.-i Tozaki and K. Nishikawa, J. Phys. Chem. $B, 2010,114,407-411$.

17 M. Kanakubo, K. R. Harris, N. Tsuchihashi, K. Ibuki and M. Ueno, J. Phys. Chem. B, 2007, 111, 2062-2069.

18 R. G. de Azevedo, J. Esperanca, V. Najdanovic-Visak, Z. P. Visak, H. J. R. Guedes, M. N. da Ponte and L. P. N. Rebelo, J. Chem. Eng. Data, 2005, 50, 997-1008.

19 L. Su, L. Li, Y. Hu, C. Yuan, C. Shao and S. Hong, J. Chem. Phys., 2009, 130, 184503.

20 L. Su, M. Li, X. Zhu, Z. Wang, Z. Chen, F. Li, Q. Zhou and S. Hong, J. Phys. Chem. B, 2010, 114, 5061-5065.

21 S. Hayashi, R. Ozawa and H. Hamaguchi, Chem. Lett., 2003, 498-499.

22 R. Ozawa, S. Hayashi, S. Saha, A. Kobayashi and H. Hamaguchi, Chem. Lett., 2003, 948-949.
23 S. Saha, S. Hayashi, A. Kobayashi and H. Hamaguchi, Chem. Lett., 2003, 740-741.

24 H.-O. Hamaguchi and R. Ozawa, Adv. Chem. Phys., 2005, 131, 85-104.

25 K. Iwata, H. Okajima, S. Saha and H.-O. Hamaguchi, Acc. Chem. Res., 2007, 40, 1174-1181.

26 R. W. Berg, M. Deetlefs, K. R. Seddon, I. Shim and J. M. Thompson, J. Phys. Chem. B, 2005, 109, 19018-19025.

27 J. D. Holbrey, W. M. Reichert, M. Nieuwenhuyzen, S. Johnston, K. R. Seddon and R. D. Rogers, Chem. Commun., 2003, 1636-1637.

28 E. R. Talaty, S. Raja, V. J. Storhaug, A. Dolle and W. R. Carper, J. Phys. Chem. B, 2004, 108, 13177-13184.

29 H.-C. Chang, C.-Y. Chang, J.-C. Su, W.-C. Chu, J.-C. Jiang and S. H. Lin, Int. J. Mol. Sci., 2006, 7, 417-424.

30 H. C. Chang, J. C. Jiang, W. C. Tsai, G. C. Chen and S. H. Lin, J. Phys. Chem. B, 2006, 110, 3302-3307.

31 H.-C. Chang, J.-C. Jiang, Y.-C. Liou, C.-H. Hung, T.-Y. Lai and S. H. Lin, J. Chem. Phys., 2008, 129, 044506.

32 H.-C. Chang, J.-C. Jiang, C.-Y. Chang, J.-C. Su, C.-H. Hung, Y.-C. Liou and S. H. Lin, J. Phys. Chem. B, 2008, 112, 4351-4356.

33 H.-C. Chang, J.-C. Jiang, J.-C. Su, C.-Y. Chang and S. H. Lin, J. Phys. Chem. A, 2007, 111, 9201-9206.

34 A. R. Choudhury, N. Winterton, A. Steiner, A. I. Cooper and K. A. Johnson, J. Am. Chem. Soc., 2005, 127, 16792-16793.

35 A. Triolo, A. Mandanici, O. Russina, V. Rodriguez-Mora, M. Cutroni, C. Hardacre, M. Nieuwenhuyzen, H.-J. Bleif, L. Keller and M. A. Ramos, J. Phys. Chem. B, 2006, 110, 21357-21364.

36 W. A. Bassett, A. H. Shen, M. Bucknum and I. M. Chou, Rev. Sci. Instrum., 1993, 64, 2340-2345.

37 C. Schmidt and M. A. Ziemann, Am. Mineral., 2000, 85, $1725-1734$.

38 Y. Imai, T. Takekiyo, H. Abe and Y. Yoshimura, Int. J. High Pressure Res., 2011, 31, 53.

39 T. Takekiyo, N. Hatano, Y. Imai, H. Abe and Y. Yoshimura, Int. J. High Pressure Res., 2011, 31, 35. 